\title{
The study on power generation technology by heat energy of reheated-based Rankine cycle
}

\author{
Xuejuan Zhao ${ }^{1, \text { a }}$,Aicheng $\mathrm{Li}^{2, \mathrm{~b}}$ \\ ${ }^{1}$ School of Aeronautic Science Engineering, Beihang University, Beijing 100191, China \\ ${ }^{2}$ Aviation Key Laboratory of Science and Technology On Aero Electromechanical System Integration, \\ Nanjing 210061, China \\ abjbhzxj@163.com, ${ }^{b} 94473124 @ q q . c o m$
}

Keywords: reheated Rankine cycle, average temperature of heat absorption, optimum reheated pressure ratio, thermodynamic performance

Abstract. This paper discussed the operation principle of reheated Rankine cycle according to the first law of thermodynamics and proposed a method to acquire the optimum reheated pressure ratio based on the highest cycle thermal efficiency. In order to verify the rationality and validity of this method, this paper selected R134a, R11 and R227ea to be the working fluids and calculated the thermodynamic performance of the reheated Rankine cycle system with using MATLAB and REFPROP. This paper also studied the thermodynamic performance of the conventional Rankine cycle system under the same conditions to compare the difference with the reheated cycle pattern.

\section{Introduction}

The most common steam dynamic cycle adopted by modern thermal power generation factories is Rankine cycle. However, the thermal efficiency of conventional Rankine cycle isn't desirable. What really matters is that the temperature of the unsaturated working fluid coming from the outlet of the pump is quite low, and it causes the low average temperature of heat absorption which makes the difference in temperature of evaporator fairly large and brings the heavy irreversible loss to the system. The direct way to increase the average temperature of heat absorption is to increase the working fluid's evaporation temperature. Considering the harm caused by the high humidity of the steam in the last part of turbine, this paper aimed at the reheated Rankine cycle to study the relevant power generation technology by heat energy.

\section{Operation principle of the reheated Rankine cycle system}

Fig. 1 is the reheated Rankine cycle system operation flowchart and the temperature-entropy diagram noted as T-S diagram.

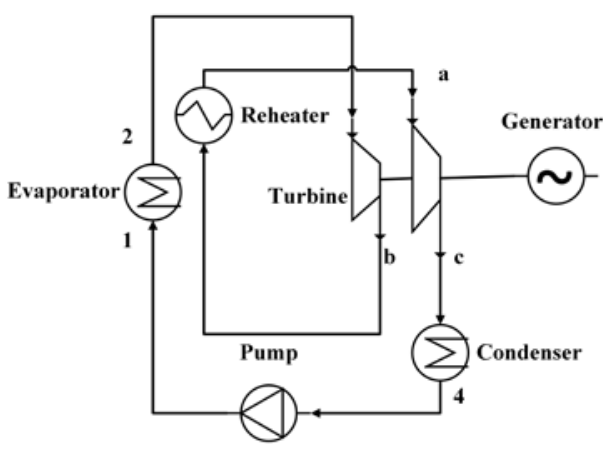

(a)System operation flowchart

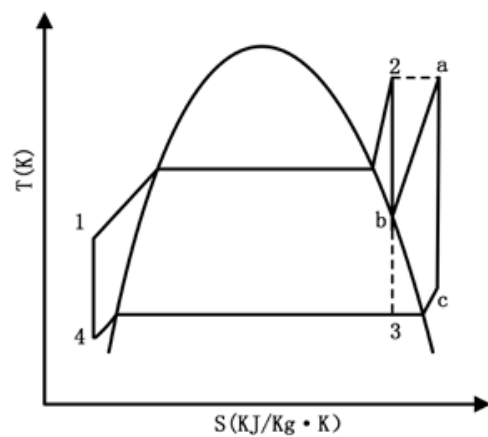

(b)Temperature-entropy diagram

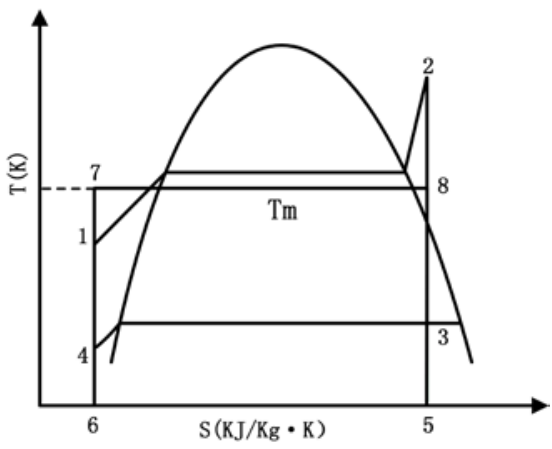

(c)Equivalent Carnot cycle diagram

Fig.1 System operation flowchart and the temperature-entropy diagram

As shown in Fig.1(a) and (b),the working fluid at point 1 comes into evaporator to absorb the heat energy and begins to evaporate. Afterwards, it becomes superheated vapor with both high 
temperature and high pressure at point 2 , and then the vapor comes into the first turbine to expand to point $b$. Make the vapor at point $b$ enter the reheater to absorb heat energy again to arrive the state of point a. It is necessary to point out that the temperature of reheated vapor marked by point a is as same as the temperature of original vapor marked by point 2 . After that, the reheated vapor continues to expand in the second turbine until the pressure turns to be the given condensation pressure. At the same time, vapor arrives at point c. Next, it enters condenser to release heat and begins to condense until it gets the state of point 4. In the end of a cycle, it comes into the pump to increase fluid's pressure to the evaporation pressure and arrives the state of point 1.From the T-S diagram, we can see that both the heat absorbing process and releasing process keep the constant pressure. In addition, the expanding process in two turbines and the compressing process in pump keep the constant entropy. To sum up the analysis above, we can acquire the fundamental mathematical model of the reheated Rankine cycle system as following:

the expanding power in turbine:

$$
W_{g}=\left(h_{2}-h_{b}\right)+\left(h_{a}-h_{c}\right)
$$

the compressing power in pump:

$$
w_{h}=h_{1}-h_{4}
$$

the net power of cycle:

$$
W_{n e t}=w_{g}-w_{h}=\left(h_{2}-h_{b}\right)+\left(h_{a}-h_{c}\right)-\left(h_{1}-h_{4}\right)
$$

the heat absorption of system:

$$
q=\left(h_{1}-h_{2}\right)+\left(h_{a}-h_{b}\right)
$$

the thermal efficiency of cycle

$$
\eta=\frac{W_{n e t}}{q}=\frac{\left(h_{2}-h_{b}\right)+\left(h_{a}-h_{c}\right)-\left(h_{1}-h_{4}\right)}{\left(h_{2}-h_{1}\right)+\left(h_{a}-h_{b}\right)}
$$

It is obvious that we can't identify the thermal efficiency of the reheated Rankine cycle is larger or smaller on earth compared with the conventional Rankine cycle directly according to Eq.5[1]. So the specific calculation about thermodynamic performance is needed.

\section{Calculation of precise value of reheated pressure ratio and thermodynamic performance}

\subsection{The principle of the algorithm.}

The definition of the reheated pressure ratio marked with $\mathrm{X}$ is given as: $X=P_{b} / P_{2}$.From Fig.1(c),we can know that what 'Tm' represents is the average temperature of working fluid in evaporation process marked as 1-2. By the concept of average temperature of heat absorption, we can use a equivalent Carnot cycle to replace the reheated Rankine cycle. As shown in Fig.1(c), the heat absorption by working fluid in evaporator is:

$$
q=\int_{1}^{2} T d s=T m \cdot\left(s_{5}-s_{6}\right)
$$

According to the meaning of integral calculus, we can know that the value of integration appeared in Eq.6 just equals the area of the polygon marked as 1-2-5-6-1, and it also equals the area of the equivalent rectangle marked as 7-8-5-6-7.It is obvious that to increase Tm is an effective path to enhance the thermal efficiency of Rankine cycle according to the efficiency characteristic of equivalent Carnot cycle. From Fig.1(b), we can see that, the conventional Rankine cycle is marked as 1-2-3-4-1.Due to the reheating process, there is an extra additional cycle marked as b-2-c-3-b.Use Tm1 and Tm2 to represent the average temperature of heat absorption in the conventional Rankine cycle and the additional cycle as following:

$$
T m 1=\frac{q}{\Delta S}=\frac{\int_{1}^{2} T d S}{\left(s_{2}-s_{1}\right)} \approx \frac{h_{2}-h_{1}}{\left(s_{2}-s_{1}\right)}
$$




$$
T m 2=\frac{q^{\prime}}{\Delta s^{\prime}}=\frac{\int_{b}^{a} T d s}{\left(s_{a}-s_{b}\right)} \approx \frac{h_{a}-h_{b}}{\left(s_{a}-s_{b}\right)}
$$

As long as the thermal efficiency of additional cycle is larger than the thermal efficiency of conventional Rankine cycle, the final thermal efficiency of full system will rise. Otherwise, it will reduce[2].In other words, if $\mathrm{Tm} 1$ is larger than Tm2, we can get a higher thermal efficiency of the reheated Rankine cycle. Thus, we can acquire a method to approach the optimum reheated pressure ratio marked as $\mathrm{X}$ attached with the maximum reheated thermal efficiency value under different working fluids and different conditions by controlling the average temperature of heat absorption.

\subsection{Illustration and analysis.}

There are several researches on the reheated pressure of reheated Rankine cycle when choosing water as the working fluid[3,4]. However, there are few relevant studies on organic fluids all over the world[5]. This paper made three different fluids named R134a, R11 and R227ea to be the working fluids of reheated Rankine cycle. The detailed calculation parameters are listed in Table 1.It is necessary to point out that the value of undercooling and overheating is selected by experience and the parameters of evaporation and condensation status are gained from REFPROP software.

Table 1 Calculation conditions and thermodynamic properties

\begin{tabular}{cccccccc}
\hline Fluids & $\begin{array}{c}\mathrm{T}_{\text {critical }} \\
\left({ }^{\circ} \mathrm{C}\right)\end{array}$ & $\begin{array}{c}\text { Evaporation } \\
\text { temperature } \\
\left({ }^{\circ} \mathrm{C}\right)\end{array}$ & $\begin{array}{c}\text { Evaporation } \\
\text { pressure } \\
(\mathrm{MPa})\end{array}$ & $\begin{array}{c}\text { Condensatio } \\
\mathrm{n} \\
\text { temeprature } \\
\left({ }^{\circ} \mathrm{C}\right)\end{array}$ & $\begin{array}{c}\text { Condensatio } \\
\mathrm{n} \\
\text { temeprature } \\
(\mathrm{MPa})\end{array}$ & $\begin{array}{c}\text { overheating } \\
\left({ }^{\circ} \mathrm{C}\right)\end{array}$ & $\begin{array}{c}\text { undercoolin } \\
\mathrm{g}\left({ }^{\circ} \mathrm{C}\right)\end{array}$ \\
\hline R134a & 101.21 & 91 & 3.301 & 30 & 0.766 & 10 & 5 \\
R11 & 198.10 & 188 & 3.804 & 30 & 0.125 & 10 & 5 \\
R227ea & 101.90 & 92 & 2.388 & 30 & 0.526 & 10 & 5 \\
\hline
\end{tabular}

\subsection{Calculation results of optimum reheated pressure ratio.}

Table 2 Results of optimum reheated pressure ratio

\begin{tabular}{cccc}
\hline Fluids & $\begin{array}{c}\text { Thermal efficiency of } \\
\text { conventional Rankine cycle }\end{array}$ & $\begin{array}{c}\text { Maximum thermal efficiency of } \\
\text { reheated Rankine cycle }\end{array}$ & $\begin{array}{c}\text { Optimum reheated pressure } \\
\text { ratio/X }\end{array}$ \\
\hline R134a & 0.12962 & 0.13126 & 0.860 \\
R11 & 0.24888 & 0.25365 & 0.735 \\
R227ea & 0.12015 & 0.12017 & 0.982 \\
\hline
\end{tabular}

As shown in Table 2,we can acquire that the reheated Rankine cycle's thermal efficiency of three different fluids are higher than the conventional Rankine cycle, but the degree of increasing isn't much too obvious. And the optimum value of $\mathrm{X}$ is larger than 0.7 , this reheated pressure value may be a little high. 


\subsection{Study on thermodynamic performance of reheated Rankine cycle.}
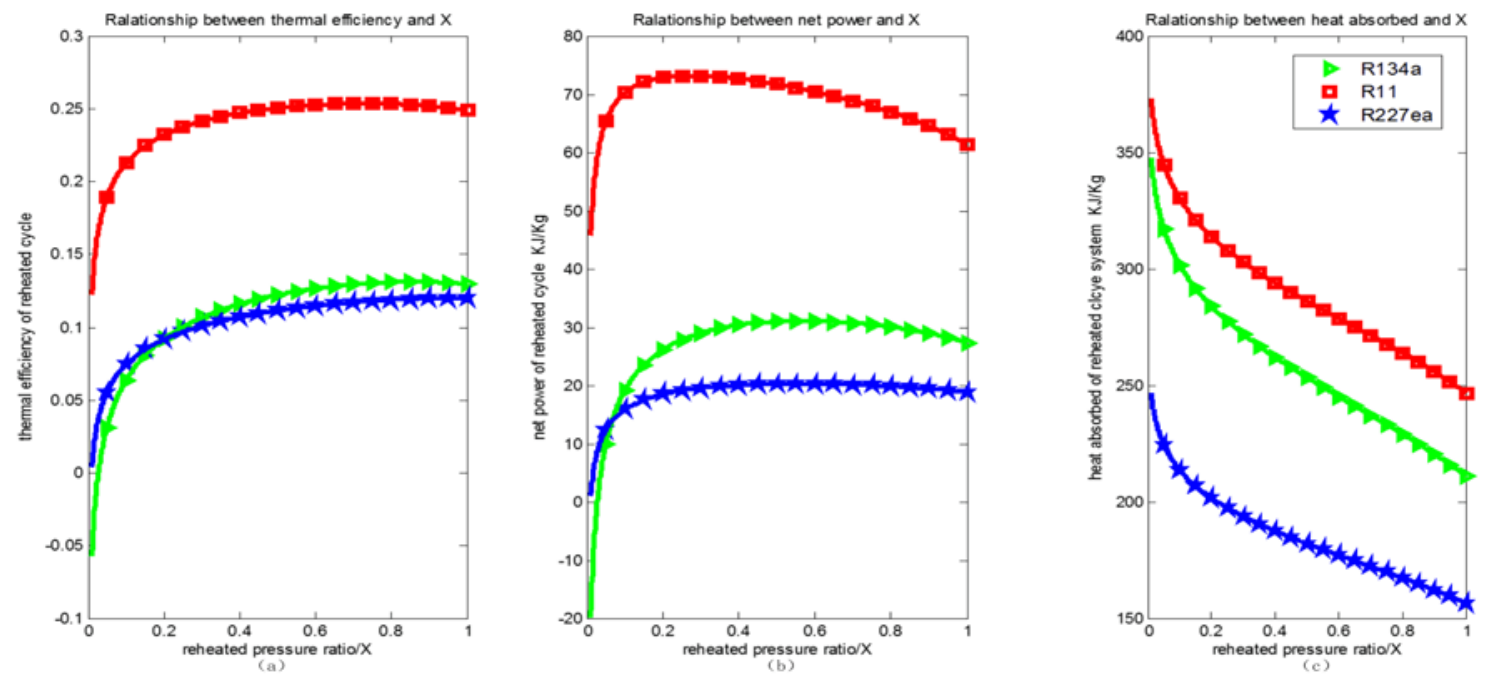

Fig.2 Thermodynamic performance of reheated Rankine cycle based on three fluids

This paper also calculated the thermodynamic performance of reheated Rankine cycle and the results are plotted to be Fig.2 as above based on three different fluids, R134a, R11 and R227ea.

From Fig.2(a),all the fluids' reheated cycle thermal efficiency showed a trend that it increased firstly and then decreased with the diminution of X. When X equals 1,the cycle is just a conventional Rankine cycle without reheating process. And then the value of $\mathrm{X}$ turns to reduce, that is to say the reheated pressure is decreasing. To sum up, the value of $\mathrm{X}$ attached to the maximum thermal efficiency is just the optimum reheated pressure. As the Fig.2(a) shown, the optimum value of $X$ is relatively high. Thus, even the efficiency of additional cycle part is larger than the conventional Rankine cycle, the effect is not obvious for total system due to the really small share to full system.

From Fig.2(b), all the fluids' net power of reheated Rankine cycle showed a similar trend that it increased firstly and then decreased with the diminution of $\mathrm{X}$. The difference is the value of $\mathrm{X}$ attached to the maximum net power is larger. Besides, the degree of net power increasing is much more tremendous. We can see these clearly in Table 3 as following.

Table 3 Comparison of net power between reheated and conventional cycle

\begin{tabular}{ccccc}
\hline Fluids & $\begin{array}{c}\text { Conventional cycle } \\
(\mathrm{KW})\end{array}$ & $\begin{array}{c}\text { Reheated cycle } \\
(\mathrm{KW})\end{array}$ & $\begin{array}{c}\text { Maximum increasing } \\
\text { rate }\end{array}$ & Corresponding X \\
\hline R134a & 27.35 & 31.09 & $13.7 \%$ & 0.563 \\
R11 & 61.37 & 73.20 & $19.3 \%$ & 0.275 \\
R227ea & 18.80 & 20.32 & $8.1 \%$ & 0.558 \\
\hline
\end{tabular}

From Fig.2(c),we can know that all the fluids' heat absorption in system increase monotonously with the diminution of $\mathrm{X}$ because of the extra additional reheating process.

\section{Summary}

1) With the diminution of reheated pressure, both the thermal efficiency and the net power of the reheated Rankine cycle increase firstly and then decrease.

2) The optimum value of $X$ determined by the maximum thermal efficiency is larger than the data determined by the maximum net power. The reheated Rankine cycle does little to promote the thermal efficiency, but can contribute a lot to the promotion of net power. Thus, it is much more effective to calculate the value of $\mathrm{X}$ by the maximum net power, especially in those situation when the power is needed a lot .

3) The reheated Rankine Cycle adds a reheating process to the system and it can optimize the thermodynamic performance of the steam dynamic cycle and increase the net power much. 
According to the calculation based on R227ea ,R134a and R11,the reheated cycle can make the net power rise by $8.1 \%, 13.7 \%$ and $19.3 \%$.

\section{Acknowledgement}

Supported by the Aeronautical Science Foundation of China, grant No.20142851031.

\section{References}

[1]. SHEN Wei-dao, JIANG Zhi-min, TONG Jun-geng. Engineering Thermodynamics. Higher Education Press,2001,p.305-307.

[2]. KANG Le-ming, TAN Yu-fei, WU Jia-zheng, ZHU Tong. Engineering Thermodynamics. China Architecture and Building Press,2007, p.190-191.

[3]. NIU Wei-dong, XU-Yu. To determine the best reheat steam pressure by the way of equivalent heat enthalpy. Shandong Electronic Technology. Vol.120(2001)No.4,p.28-30.

[4]. GUO Jiang-long, ZHANG Shu-fang, SONG Zhi-ping. The mathematic fundamental of constant-heat equivalent heat drop method and its model for matrix analysis. Proceedings of the CSEE. Vol.24(2004)No.3,p.210-215.

[5]. XU Jie, LI Xin-yu, GU Cao, SONG Jia-fang. Determination of optimal reheating pressure in organic Rankine cycle system. Journal of Tianjin Polytechnic University. Vol.28 (2009) No.6, p.83-85. 